\title{
A Novel Control Strategy of DFIG Based on the Optimization of Transfer Trajectory at Operation Points in the Islanded Power System
}

\author{
Zengqiang Mi, ${ }^{1}$ Liqing Liu, ${ }^{1}$ He Yuan, ${ }^{1}$ Ping Du, ${ }^{2}$ and Yuliang Wan ${ }^{2}$ \\ ${ }^{1}$ State Key Laboratory of Alternate Electrical Power System with Renewable Energy Sources, Baoding 071003, China \\ ${ }^{2}$ Power Dispatching Control Center, State Grid East Inner Mongolia Electric Power Company Limited, Hohhot 010020, China \\ Correspondence should be addressed to Liqing Liu; liuliqing328@163.com
}

Received 16 October 2015; Revised 28 December 2015; Accepted 6 January 2016

Academic Editor: Ivan Kyrchei

Copyright ( $\odot 2016$ Zengqiang Mi et al. This is an open access article distributed under the Creative Commons Attribution License, which permits unrestricted use, distribution, and reproduction in any medium, provided the original work is properly cited.

A novel control strategy based on the optimization of transfer trajectory at operation points for DFIG is proposed. Aim of this control strategy is to reduce the mechanical fatigue of DFIG caused by the frequent adjustment of rotating speed and pitch angle when operating in the islanded power system. Firstly, the stability of DFIG at different operation points is analyzed. Then an optimization model of transfer trajectory at operation points is established, with the minimum synthetic adjustment amount of rotating speed and pitch angle as the objective function and with the balance of active power and the stability of operation points as the constraint conditions. Secondly, the wind speed estimator is designed, and the control strategy of pitch system is improved to cooperate with the indirect stator flux orientation control technology for rotor-side inverter control. Then by the coordination control of its rotating speed and pitch angle, an operation trajectory controller is established to ensure the islanded operation of DFIG along the optimal transfer trajectory. Finally, the simulation results show that the proposed control strategy is technical feasibility with good performance.

\section{Introduction}

The islanded operation is a significant operation mode of wind turbine, and this can widen the applied range of wind turbine [1]. It can improve the service ability, reduce the cost of power supply, and protect the environment by composing an islanded power system with wind turbine in some remote regions or islands $[2,3]$. And for some areas that lack emergency power supply, their economic losses caused by the power grid failure can be reduced when the important local load is supplied by the wind turbine $[4,5]$. So it is significant to make an intensive study of the control strategy for wind turbine to operate in the islanded operation mode.

The doubly fed induction generator based wind turbine (DFIG) is currently the most widely used type of unit [6], and some researches about the islanded operation control strategy of DFIG have been carried out at home and abroad. In [7], the battery energy storage system (BESS) is connected in parallel with the DC link of DFIG inverter, and the hybrid system can operate in different modes and has the ability to supply power for the load independently. The coordinate control strategies of wind turbines and energy storage systems for stabilizing the islanded power system are proposed in $[8,9]$. In [10-12], with the droop control strategy introduced, the DFIG can respond to the frequency and voltage changes of the isolated power system and keep its voltage and frequency to be stable, so the DFIG can continue to supply the load around in the case of disconnection from power grid. Through applying the control strategies proposed in [7-12], the DFIG can operate in the islanded mode. However, the strategies only make the DFIG to be similar with a current source essentially, so that a large power source is needed to sustain the voltage of islanded power system. An indirect stator flux orientation (ISFO) control strategy which is suitable for the doubly fed induction generator is proposed in $[13,14]$; it can enable the doubly fed induction generator with voltage source characteristics 
to control the frequency and amplitude of its stator voltage independently. The DFIG can obtain the ability to supply the load independently with the application of ISFO control strategy $[15,16]$. Operating in the islanded mode, the frequent adjustment of rotating speed and pitch angle may produce mechanical fatigue on the DFIG and affect its service life seriously.

In this paper, a control strategy based on the optimization of transfer trajectory at operation points for a standalone DFIG is proposed. Through applying this control strategy to coordinately regulate the rotating speed and pitch angle, the DFIG can autonomously operate along the transfer trajectory with the minimum synthetic adjustment amount of rotating speed and pitch angle. This paper is structured as follows. In Section 2, the mathematical model of DFIG is outlined, and the optimization model of transfer trajectory at operation points is established by the stability analysis of operation points. In Section 3, the designed control strategy is described. It mainly contains the wind speed estimator, the control unit of rotor-side converter and variable pitch system, and the operation trajectory controller. Simulation results are given and discussed in Section 4. Finally, conclusions are presented in Section 5 .

\section{Transfer Trajectory Optimization of DFIG Operation Point}

2.1. Mathematical Model of DFIG. The aerodynamic power captured by the turbine is as follows:

$$
P_{a}=\frac{1}{2} \rho \pi R^{2} C_{p}(\lambda, \beta) V_{W}^{3}=T_{a} \omega_{r}
$$

where $P_{a}$ is the aerodynamic power, $\rho$ is the air density, $R$ is the rotor radius, $C_{p}$ is the aerodynamic power performance coefficient which is the function of tip speed ratio $\lambda$ and pitch angle $\beta, V_{W}$ is the wind speed, $T_{a}$ is the aerodynamic torque, and $\omega_{r}$ is the rotating speed of the turbine.

The aerodynamic power performance coefficient $C_{p}$ is calculated according to the following equation:

$$
\begin{aligned}
C_{p} & =c_{1}\left(c_{6} \lambda+\frac{\left(-c_{4}-c_{3} a_{1}+c_{2} a_{2}\right)}{\exp \left(c_{5} a_{2}\right)}\right), \\
\lambda & =\frac{\omega_{r} R}{V_{W}}, \\
a_{1} & =2.5+\beta, \\
a_{2} & =\frac{1}{\left(\lambda+c_{7} a_{1}\right)}-\frac{c_{8}}{\left(1+a_{1}^{3}\right)},
\end{aligned}
$$

where $c_{1}-c_{8}$ are constants related to the aerodynamic characteristics of the wind wheel.
The dynamic behavior of the drive train can be described with a two-mass model [17]:

$$
\begin{aligned}
J_{t} \dot{\omega}_{r} & =T_{a}-D_{m}\left(\omega_{r}-\frac{\omega_{g}}{n}\right)-K_{m} \theta \\
J_{g} \dot{\omega}_{g} & =\frac{1}{n}\left[D_{m}\left(\omega_{r}-\frac{\omega_{g}}{n}\right)+K_{m} \theta\right]-F_{g} \omega_{g}-T_{e}, \\
\dot{\theta} & =\omega_{r}-\frac{\omega_{g}}{n},
\end{aligned}
$$

where $J_{t}$ and $J_{g}$ are the turbine and generator inertia, respectively, $D_{m}$ is damping coefficient, $K_{m}$ is the shaft elastic coefficient, $F_{g}$ is the friction coefficient of generator, $T_{e}$ is the electromagnetic torque of generator, $\omega_{g}$ is the generator speed, $n$ is the gearbox ratio, and $\theta$ is the shaft deformation angle.

The equations of doubly fed induction generator written in a synchronously rotating $d$-q reference frame are expressed as follows [13]:

$$
\begin{aligned}
& u_{s d}=R_{s} i_{s d}+\frac{d \psi_{s d}}{d t}-\omega_{1} \psi_{s q}, \\
& u_{s q}=R_{s} i_{s q}+\frac{d \psi_{s q}}{d t}+\omega_{1} \psi_{s d}, \\
& u_{r d}=R_{r} i_{r d}+\frac{d \psi_{r d}}{d t}-\left(\omega_{1}-\omega_{r}\right) \psi_{r q}, \\
& u_{r q}=R_{r} i_{r q}+\frac{d \psi_{r q}}{d t}+\left(\omega_{1}-\omega_{r}\right) \psi_{r d}, \\
& \psi_{s d}=L_{s} i_{s d}+L_{m} i_{r d}=L_{m} i_{m s}, \\
& \psi_{s q}=L_{s} i_{s q}+L_{m} i_{r q}, \\
& \psi_{r d}=L_{m} i_{s d}+L_{r} i_{r d}, \\
& \psi_{r q}=L_{m} i_{s q}+L_{r} i_{r q},
\end{aligned}
$$

where $u_{s d}, u_{s q}, u_{r d}, u_{r q}$ are the $d q$ components of stator voltage and rotor voltage, respectively, $\psi_{s d}, \psi_{s q}, \psi_{r d}, \psi_{r q}$ are the $d q$ components of stator flux and rotor flux, respectively, $i_{s d}, i_{s q}, i_{r d}, i_{r q}$ are the $d q$ components of stator current and rotor current, respectively, $R_{s}$ and $R_{r}$ are the stator resistance and rotor resistance, $L_{s}, L_{r}$, and $L_{m}$ are the stator inductance, rotor inductance, and the mutual inductance, $\omega_{1}$ is the synchronous speed, and $i_{m s}$ is the equivalent stator magnetizing current.

2.2. Stability Analysis of DFIG Operation Points. Based on the historical statistics data of wind speed and load in the islanded power system, if the capacity of DFIG is configured reasonably, the DFIG can satisfy the reactive power demand of load. On this basis, the specific active power can be output by adjusting the rotating speed and pitch angle of DFIG. It is 


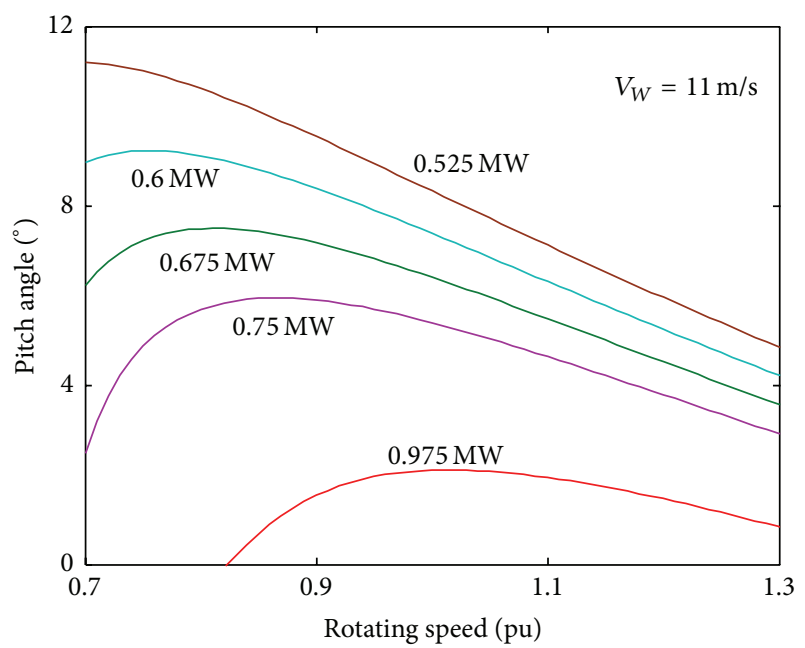

FIGURE 1: The relationship between rotating speed and pitch angle for different aerodynamic power.

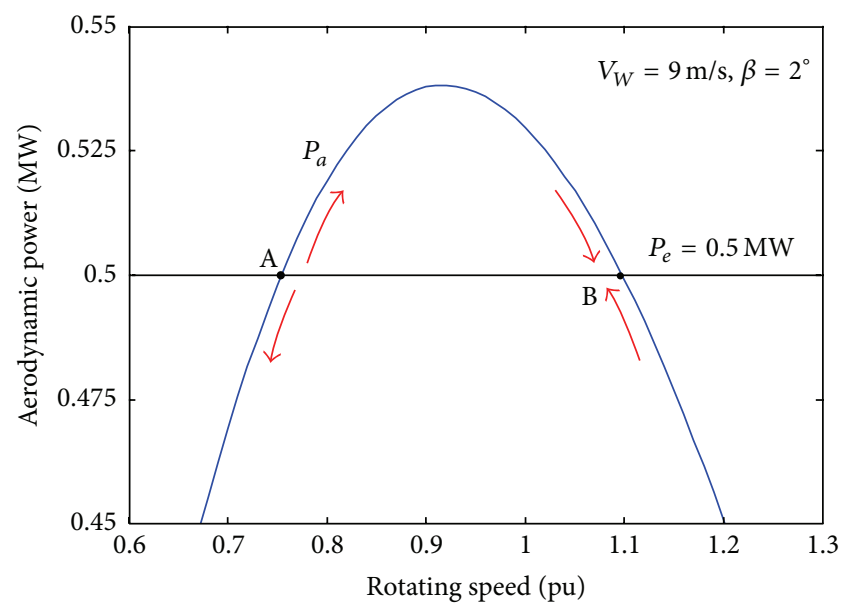

FIGURE 2: The stability analysis of operation points.

known from (1) and (2) that, for a certain wind speed, the aerodynamic power captured by the turbine is a nonlinear function of the rotating speed $\omega_{r}$ and pitch angle $\beta$ and this is shown in Figure 1.

For specific wind speed and captured aerodynamic power, DFIG can operate with different rotating speeds and pitch angles, namely, different operating points. However, the DFIG is not able to operate at some operation points stably (shown in Figure 1), and the following analysis is made. As shown in Figure 2, when the wind speed is $9 \mathrm{~m} / \mathrm{s}$, there are two operation points called A and B where DFIG can absorb $0.5 \mathrm{MW}$ power from the wind. For operation point A,

$$
\left.\frac{\partial P_{a}}{\partial \omega_{r}}\right|_{\left(\omega_{r A}, \beta\right)}>0 .
$$

And for operation point B,

$$
\left.\frac{\partial P_{a}}{\partial \omega_{r}}\right|_{\left(\omega_{r A}, \beta\right)} \leq 0 .
$$

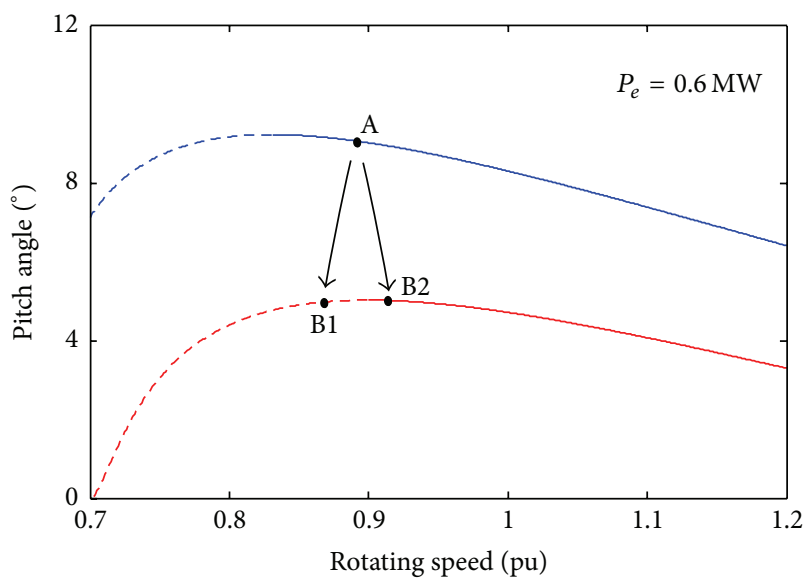

Figure 3: The transfer trajectories of operation point for DFIG.

When DFIG operates at point A, the captured aerodynamic power and the rotating speed would rise following the increasing wind speed. As shown in (5), the increasing rotating speed will drive DFIG to capture more aerodynamic power, and then the rotating speed will be further increased, which makes the turbine gradually deviate from operation point $A$. When the wind turbine operates at point $B$, the increase of wind speed will also result in the rise of rotating speed. But as shown in (6), the rise of rotating speed would decrease the aerodynamic power absorbed by DFIG, and this may force DFIG to return to operation point $\mathrm{B}$. The operation condition is similar to the one above when wind speed is reduced. Thus operation point $\mathrm{A}$ is not the stable one while operation point B is. Through analysis, to ensure that DFIG stably operate at a certain point, (6) is necessary.

\subsection{Transfer Trajectory Optimization of DFIG Operation} Point. The operation point will be adjusted according to the fluctuation of wind speed and load when DFIG operates in the islanded mode. As shown in Figure 3, the wind speed is $10 \mathrm{~m} / \mathrm{s}$ at $t 0$, and DFIG operates stably at point A with the output power $0.6 \mathrm{MW}$. The wind speed reduces to $10 \mathrm{~m} / \mathrm{s}$ at $t 1$, so the wind turbine operation point needs to be transferred from point $A$ to another operation point on the red line in order to keep its output power unchanged. The red dotted line is the set of unstable operation points, while the solid line presents the stable ones. The synthetic adjustment amount of rotating speed and pitch angle will be minimized if the operation point is transferred from point A to B1 or B2. But $\mathrm{B} 1$ is not the stable one, so transferring operation point to B2 can keep the output power unchanged and minimize the synthetic adjustment of rotating speed and pitch angle.

Therefore the optimization model of transfer trajectory at operation points is established to obtain the optimal transfer trajectory that DFIG operates along, and the objective function of which is the minimum of the synthetic adjustment amount of rotating speed and pitch angle between two adjacent times. The constraint conditions include the balance of active power and the stability of operation points. The model is shown from (7) to (12). Equation (7) is the objective 


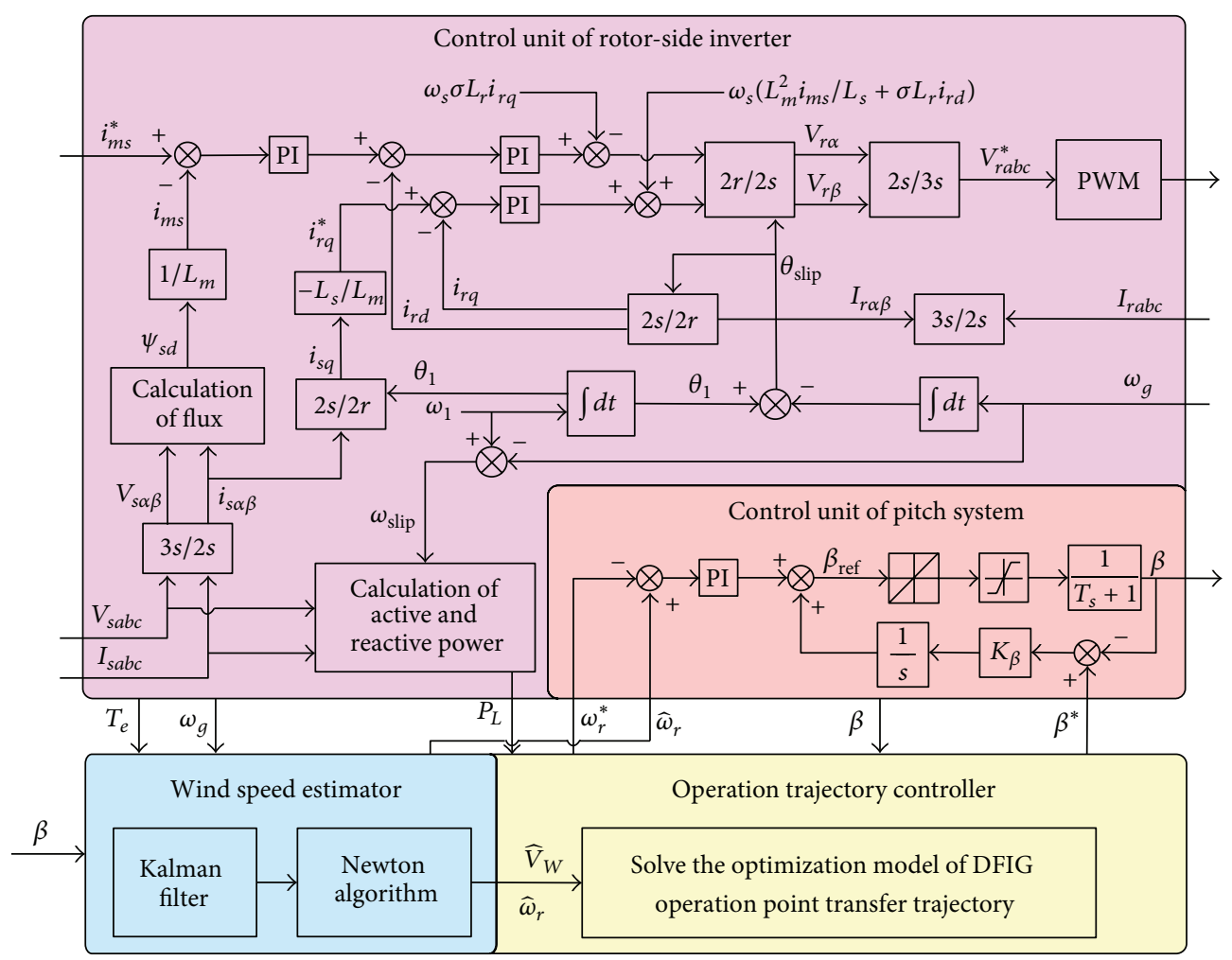

FIGURE 4: Schematic of the islanded operation control strategy of DFIG.

function, in which two terms present the rotating speed and pitch angle adjustment amount between two adjacent times, respectively. Equations (8) and (9) are the restrictions of pitch angle and rotating speed, respectively. The restriction described in (10) can ensure the stable operation of DFIG at the selected operation point. Equations (11) and (12) are the active power balance constraints

$$
\begin{aligned}
& J_{1}=\min \left(a_{\omega} \frac{\left|\omega_{r, k}^{*}-\omega_{r, k-1}\right|}{\omega_{r, \max }}+a_{\beta} \frac{\left|\beta_{k}^{*}-\beta_{k-1}\right|}{\beta_{\max }}\right), \\
& \beta_{\min } \leq \beta_{k}^{*} \leq \beta_{\max }, \\
& \omega_{r, \min } \leq \omega_{r, k}^{*} \leq \omega_{r, \max }, \\
& \left.\frac{\partial P_{a, k}^{*}}{\partial \omega_{r, k}^{*}}\right|_{\left(\omega_{r, k}^{*}, \beta_{k}^{*}\right)} \leq 0, \\
& P_{a, k}^{*}=\frac{1}{2} \rho \pi R^{2} C_{p}\left(\omega_{r, k}^{*}, \beta_{k}^{*}\right) V_{W, k}^{3}, \\
& P_{a, k}^{*}-\left(1+L_{x}\right) P_{L, k}^{*}=0,
\end{aligned}
$$

where $\omega_{r, k}^{*}, \beta_{k}^{*}$ are the control commands of rotating speed and pitch angle at next moment, respectively, $\omega_{r, k-1}, \beta_{k-1}$ are the rotating speed and pitch angle at the present moment, respectively, and $\omega_{r, \max }, \omega_{r, \min }, \beta_{\max }, \beta_{\min }$ are the maximum and minimum of rotor speed and pitch angle, respectively. $a_{\omega}$, $a_{\beta}$ are weight values of rotating speed and pitch angle, respectively, and set to be 0.1 and 0.9 according to experimental comparison. $L_{x}$ is the internal power loss coefficient, which is between 0.03 and $0.05 . P_{L, k}^{*}$ is the active power requirement of load at next moment and $P_{a, k}^{*}$ is the captured aerodynamic power of DFIG at next moment. $V_{W, k}^{*}$ is the wind speed at next moment, which can be estimated by establishing a state observer [17].

\section{Islanded Operation Control Strategy of DFIG}

A control strategy for DFIG which operates in the islanded mode, based on the optimization of transfer trajectory at operation points, is proposed in this paper (shown in Figure 4). A wind speed estimator using Kalman filter (KF) and Newton-Raphson (NR) algorithms is established to estimate the wind speed and rotating speed. The ISFO control technology is applied to control the rotor-side inverter of DFIG, and the traditional control strategy of pitch system is modified. Then by the coordination control of rotating speed and pitch angle, an operation trajectory controller is established to ensure the islanded operation of DFIG along the optimal transfer trajectory. 
3.1. Wind Speed Estimator. Wind turbines are usually equipped with anemometers which can measure the wind speed. However, the measurement data are not accurate enough because of the aerodynamic turbulent phenomena caused by the rotating blades of wind turbine. Moreover, the wind measured by anemometers is not exactly equal to the component that transfer power to the turbine rotor. Therefore, in order to obtain a good performance in the overall control loop, it is necessary to exploit the indirect information to precisely estimate the wind speed. KF is adopted in the wind speed estimator to estimate the aerodynamic torque $\widehat{T}_{a}$ and rotating speed $\widehat{\omega}_{r}$, and then the effective wind speed could be derived from $\widehat{T}_{a}$ and $\widehat{\omega}_{r}$ with NR method [17].

For the estimator design, it is assumed that the rotating speed and electromagnetic torque of generator are available through measurements, and only the generator rotating speed is a noisy measurement. With the aerodynamic torque $T_{a}$ as an additional state, the augmented state-space model is given as follows:

$$
\begin{gathered}
{\left[\begin{array}{c}
\dot{\omega}_{r} \\
\dot{\omega}_{g} \\
\dot{\theta} \\
\dot{T}_{a}
\end{array}\right]=\left[\begin{array}{cccc}
-\frac{D_{m}}{J_{t}} & \frac{D_{m}}{n J_{t}} & -\frac{K_{m}}{J_{t}} & \frac{1}{J_{t}} \\
\frac{D_{m}}{n J_{g}} & -\frac{D_{m}+n^{2} F_{g}}{n^{2} J_{g}} & \frac{K_{m}}{n J_{g}} & 0 \\
1 & -1 & 0 & 0 \\
0 & 0 & 0 & 0
\end{array}\right]\left[\begin{array}{c}
\omega_{r} \\
\omega_{g} \\
\theta \\
T_{a}
\end{array}\right]+\left[\begin{array}{c}
0 \\
-\frac{1}{J_{g}} \\
0 \\
0
\end{array}\right] T_{e}+\left[\begin{array}{l}
0 \\
0 \\
0 \\
\zeta
\end{array}\right],} \\
y=\left[\begin{array}{llll}
0 & 1 & 0
\end{array}\right]\left[\begin{array}{c}
\omega_{r} \\
\omega_{g} \\
\theta \\
T_{a}
\end{array}\right]+v,
\end{gathered}
$$

where $\zeta, v$ are the process noisy and measurement noisy, respectively.

Equation (13) can be discretized by zero-holding method with sampling time $T_{s}$, and then the discretized model can be used in an estimation algorithm by applying the KF. Finally, the wind speed estimation $\widehat{V}_{W}$ can be obtained by resolving (14) with NR method:

$$
\widehat{T}_{a} \widehat{\omega}_{r}-\frac{1}{2} \rho \pi R^{2} C_{p}(\lambda, \beta) \widehat{V}_{W}^{3}=0 .
$$

3.2. Rotor-Side Inverter Control. When ISFO control technology is adopted in the control unit of rotor-side inverter, the amplitude and frequency of DFIG stator voltage can be controlled by regulating its $i_{m s}$ and $i_{r q}$. The $d$-axis in synchronous rotating reference frame is orientated in stator flux vector of generator, and the following equations are established:

$$
\begin{aligned}
& i_{s d}=\frac{L_{m}}{L_{s}}\left(i_{m s}-i_{r d}\right), \\
& i_{r q}=-\frac{L_{s}}{L_{m}} i_{s q} .
\end{aligned}
$$

Replacing $i_{s d}$ in stator voltage equation with (15), then (17) can be obtained:

$$
\frac{L_{s}}{R_{s}} \frac{d i_{m s}}{d t}+i_{m s}=i_{r d}+\frac{L_{s}}{R_{s} L_{m}} u_{s d}
$$

Neglecting the voltage drop on the stator resistance, then the stator voltage equations can be expressed as follows:

$$
\begin{aligned}
& u_{s d} \approx 0, \\
& u_{s q} \approx \omega_{1} \psi_{s d}=\omega_{1} L_{m} i_{m s} .
\end{aligned}
$$

Neglecting the differential term of $i_{m s}$, the rotor voltage equations can be expressed as follows:

$$
\begin{aligned}
& u_{r d}=R_{r} i_{r d}+\sigma L_{r} \frac{d i_{r d}}{d t}-\omega_{s} \sigma L_{r} i_{r q}, \\
& u_{r q}=R_{r} i_{r q}+\sigma L_{r} \frac{d i_{r q}}{d t}+\omega_{s}\left(\frac{L_{m}^{2}}{L_{s}} i_{m s}+\sigma L_{r} i_{r d}\right),
\end{aligned}
$$

where $\omega_{s}=\omega_{1}-\omega_{g}$, which presents the slip angular speed.

The rotor current $i_{r d}$ can be controlled by adjusting $u_{r d}$, and then the stator voltage amplitude can be controlled by regulating $u_{r d}$ to make $i_{m s}$ track the reference value $i_{m s}^{*}$. The rotor current $i_{r q}$ can be controlled by adjusting $u_{r q}$. Regulating $i_{r q}$ to track the reference value $i_{r q}^{*}$ calculated via (16) will force the orientation of the reference frame along the stator flux vector position, and then the control of stator voltage frequency is achieved indirectly. This means that the stator flux angle does not have to be derived from integration of the stator voltages; instead, it can be derived directly from a free running integral of the stator voltage frequency demand $\omega_{1}(50 \mathrm{~Hz})$. The control strategy is shown in Figure 4. In addition, the traditional control strategy is adopted in the grid-side inverter control to stabilize the DC link voltage.

3.3. Pitch System Control. As shown in (1) and (2), for specific wind speed and aerodynamic power captured by the turbine, its pitch angle could be controlled indirectly by regulating the rotating speed. Therefore the DFIG can operate along the selected transfer trajectory by regulating $\omega_{r}$ and $\beta$ to track the reference value $\omega_{r}^{*}$ and $\beta^{*}$ calculated from the operation trajectory controller. In this paper, $\omega_{r}^{*}$ is used as the reference value of the pitch control unit and $\beta$ is regulated to make the rotating speed estimation value $\widehat{\omega}_{r}$ track the reference value $\omega_{r}^{*}$. However, there will always exist a little slight error between the real pitch angle $\beta$ and reference value $\beta^{*}$ because of some reasons such as the inertia of the pitch system actuator. In order to reduce the tracking error, a compensation term is introduced into the pitch control, and the integration coefficient $K_{\beta}$ is set to be 0.01 .

3.4. Operation Trajectory Controller of DFIG. In order to obtain the optimal transfer trajectory of DFIG, the operation trajectory controller based on the optimization model of transfer trajectory at operation points is established. As shown in Figure 4, the input of the operation trajectory 
controller contains $\widehat{V}_{W}$ and $\widehat{\omega}_{r}$ sampled from the wind speed estimator and $P_{L}$ and $\beta$ sampled from the control unit of rotor-side converter and pitch system, respectively. The optimization model of transfer trajectory at operation points is solved in real time, and the optimization results, namely, the control commands of $\omega_{r}^{*}$ and $\beta^{*}$, are sent to the control unit of pitch system. Then the coordinate control of rotating speed and pitch angle could be achieved through the control unit of rotor-side inverter and pitch system, and this would make the wind turbine track the selected operation transfer trajectory.

The interior point method has the characteristics of fast calculation, strong robustness, and global convergence $[18,19]$. It is widely used in solving the large nonlinear optimization model, such as the optimal power flow model of power system [20], the optimal coordinated voltage control model [21], and the restoring power flow model of power system [22]. Therefore, in order to obtain the optimal transfer trajectory of DFIG, the interior point method is applied to get the global optimal solution of the transfer trajectory optimization model.

In this paper, the Ipopt toolbox [23] in MATLAB is used in the operation trajectory controller to solve the optimization model of transfer trajectory at operation points. The Ipopt toolbox is based on the interior point method. Through a large number of simulations, it shows that solving the model generally takes $0.02-0.05 \mathrm{~s}$ once. Therefore, $0.1 \mathrm{~s}$ is taken as the sampling time of the operation trajectory controller, which can ensure obtaining the solution of the optimization model within one sample cycle. In addition, it is rational to assume that the use of lower level software suitable for control system practical implementation would further decrease the calculation time.

\section{Simulation Results}

The islanded power system shown in Figure 5 is simulated to verify the feasibility of the control strategy of DFIG proposed in this paper. In Figure 5, the DFIG whose rated power is 1.55 MVA can supply the controllable load L1 through the $0.69 / 10 \mathrm{kv}$ box-type transformer $\mathrm{T} 1$, the $0.1 \mathrm{~km}$ transmission line, and the $10 / 0.4 \mathrm{kv}$ transformer T2. The controllable load $\mathrm{L} 1$ has been simulated by the inverter and the DC source. The simulation results are shown in Figure 6.

An actual measured time series of wind speed is used in this paper, and its sample period is $1 \mathrm{~s}$. The wind speed data between two sample points is obtained by linear interpolation. As shown in Figures 6(a) and 6(b), the actual wind speed and rotating speed of DFIG can be precisely estimated by the wind speed estimator designed in this paper. It is obvious that the error of the designed wind speed estimator is adequately small to ensure better performance of the overall control loop. The control strategy of pitch system was switched to the proposed one in this paper from the one mentioned in [10]. Figures 6(h) and 6(i) show that, with ISFO control technology adopted in the control unit of DFIG rotor-side inverter, the actual values of the equivalent stator magnetizing current and the $q$-axis component of rotor current could be regulated to track their reference values, respectively. Then the amplitude

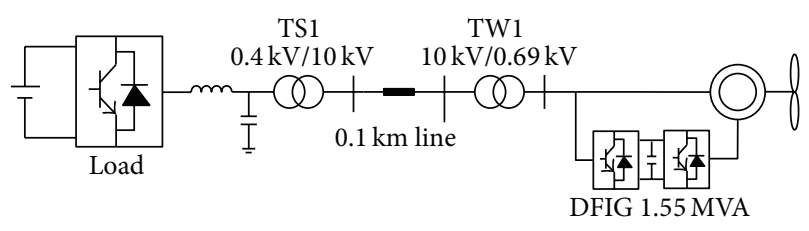

FIGURE 5: Diagram of the islanded power system.

and frequency of DFIG stator voltage could be stabilized as shown in Figures 6(f) and 6(g), and the active power and reactive power demand of load can be satisfied as shown in Figures 6(d) and 6(e).

Due to the wind speed in Figure 6(a) and active power demand of load in Figure 6(d) changing over time, the rotating speed and pitch angle of DFIG need to be adjusted to keep the balance between the captured aerodynamic power and active power output of DFIG. As shown in Figures 6(b)$6(d)$, on the basis of the active power requirement of load satisfied, the rotating speed and pitch angle of DFIG can track the reference values offered by the operation trajectory controller. Figures $6(\mathrm{k})$ and $6(\mathrm{l})$ show that the operation trajectory controller could always obtain the global optimal solution of the optimization model within $0.1 \mathrm{~s}$, and it ensures the selected operation transfer trajectory to be the optimal one that has the minimum synthetic adjustment amount of rotating speed and pitch angle. Figure 6(j) shows that the DC link voltage can be stabilized by the control of the grid-side inverter, and it could provide slip power for the rotor-side inverter. Therefore, DFIG could autonomously operate in the islanded mode along the optimal trajectory by adopting the control strategy proposed in this paper.

In order to evaluate the performance of the proposed control strategy, with the same simulation conditions employed, the control strategies of pitch system proposed in $[10,16]$ (shown in Figure 7) are also simulated. Figure 8 shows that the control strategy proposed in this paper could make the rotating speed and pitch angle track their reference values more quickly and accurately. Moreover, three evaluation indexes are defined as follows to quantitatively compare the adjustment amount of the rotating speed and pitch angle, including the adjustment amount of rotating speed $\Delta \omega_{r}$, the adjustment amount of pitch angle $\Delta \beta$, and the synthetic adjustment amount $\Delta z$. It is obvious that when DFIG operates in the islanded mode, its synthetic adjustment amount of the rotating speed and pitch angle could be reduced with the application of the control strategy proposed in this paper as shown in Table 1:

$$
\begin{aligned}
\Delta \omega_{r} & =\sum_{i=1}^{K} \frac{\left|\omega_{r, k}-\omega_{r, k-1}\right|}{\omega_{r, \max }}, \\
\Delta \beta & =\sum_{i=1}^{K} \frac{\left|\beta_{k}-\beta_{k-1}\right|}{\beta_{\max }}, \\
\Delta z & =\Delta \omega_{r}+\Delta \beta .
\end{aligned}
$$




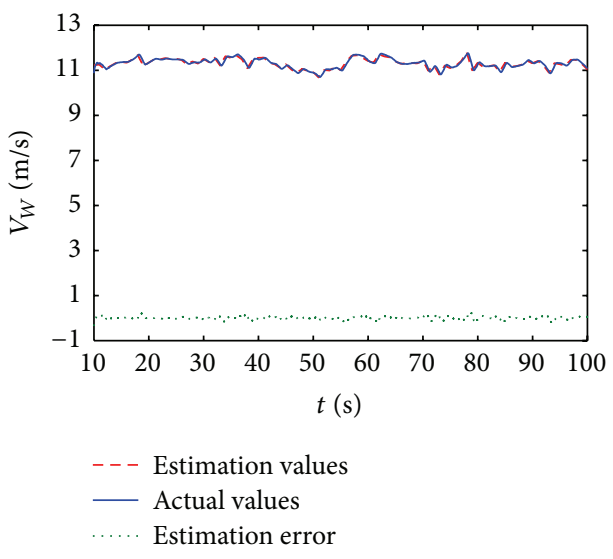

(a) Wind speed

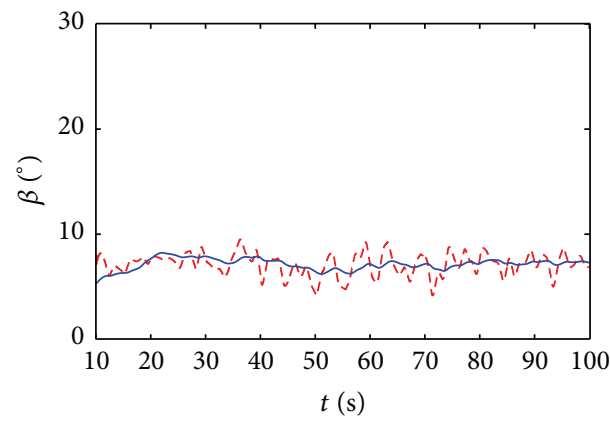

- - Reference values

_ Actual values

(c) Pitch angle

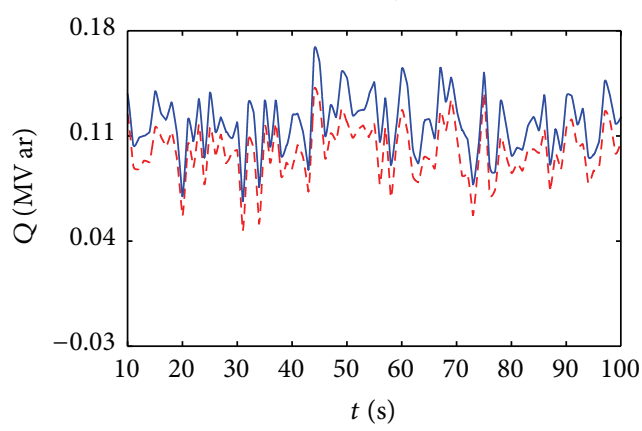

- - - Load demand

— Output of DFIG

(e) Reactive power

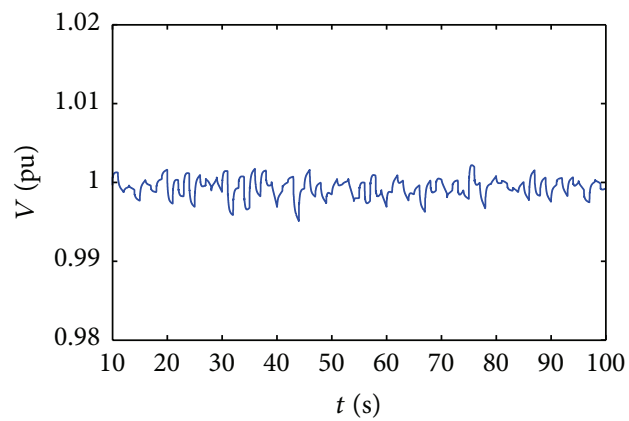

(g) Stator voltage

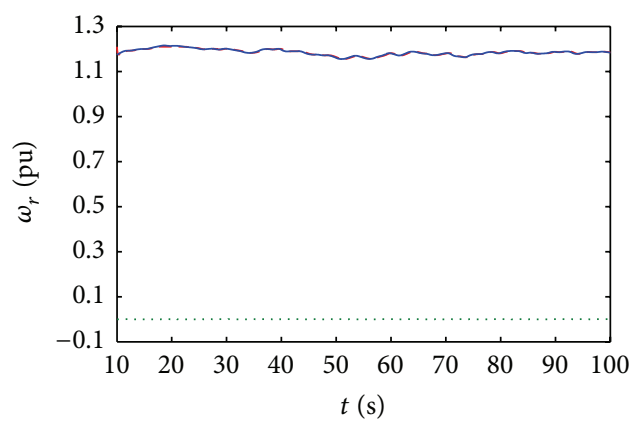

- - - Reference values

_ Actual values Estimation error

(b) Rotating speed

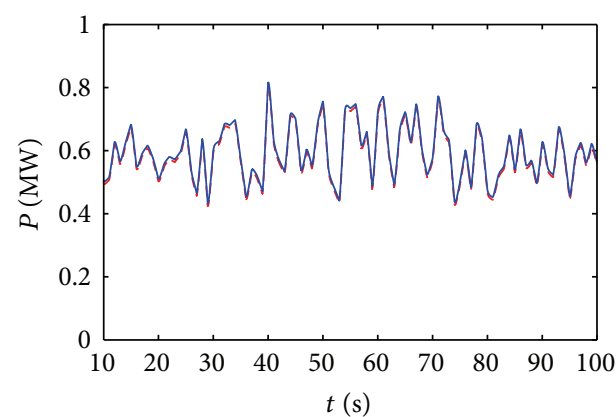

- - - Load demand

— Output of DFIG

(d) Active power

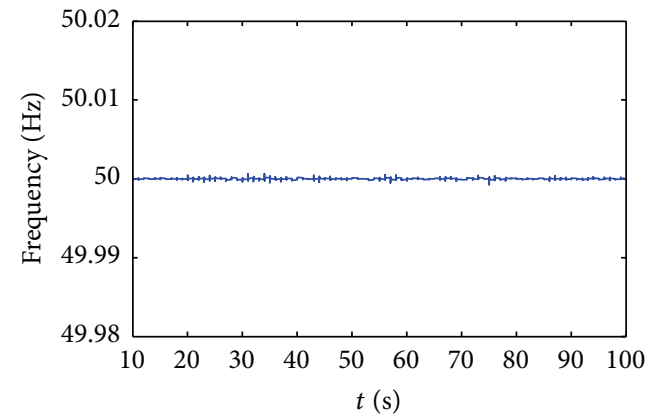

(f) Frequency

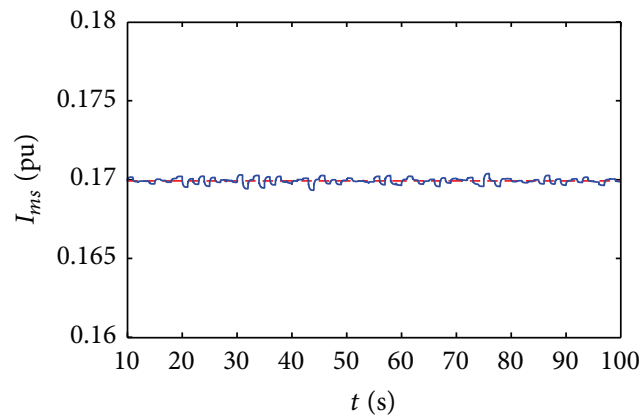

- - Reference values

_ Actual values

(h) Equivalent stator magnetizing current

Figure 6: Continued. 

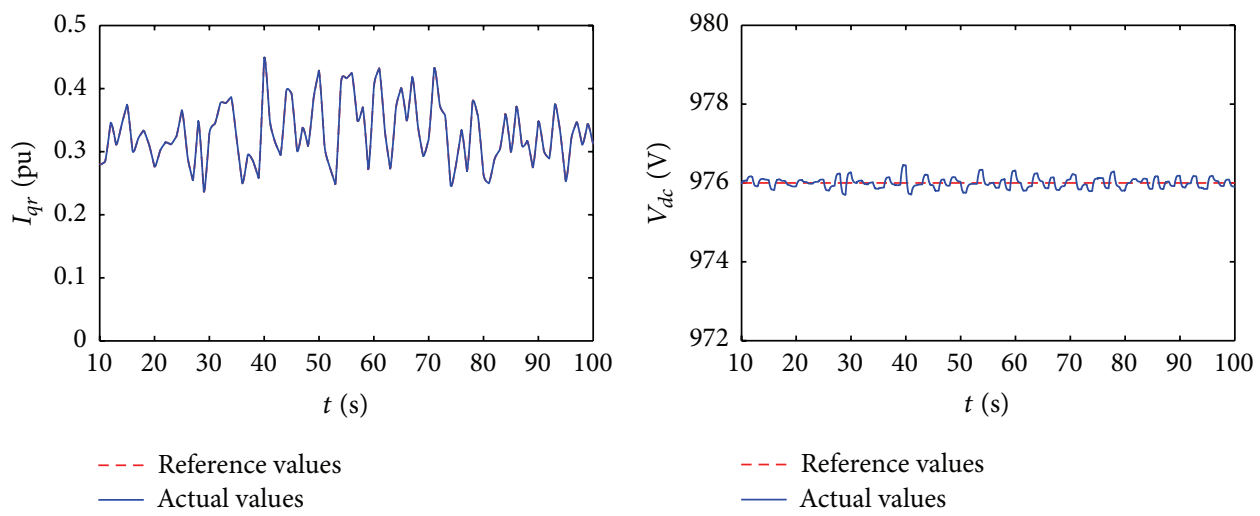

(i) $q$-axis component of rotor current

(j) DC link voltage

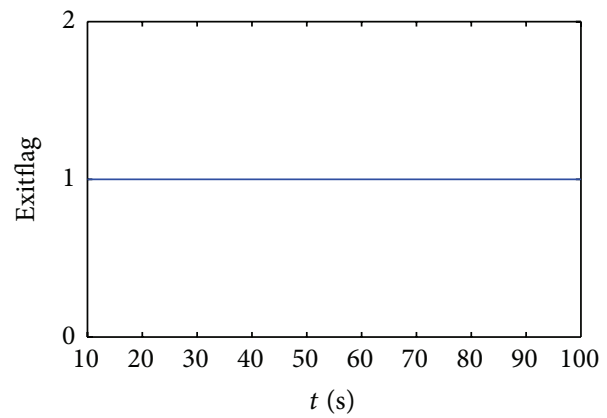

(k) Feasible solution

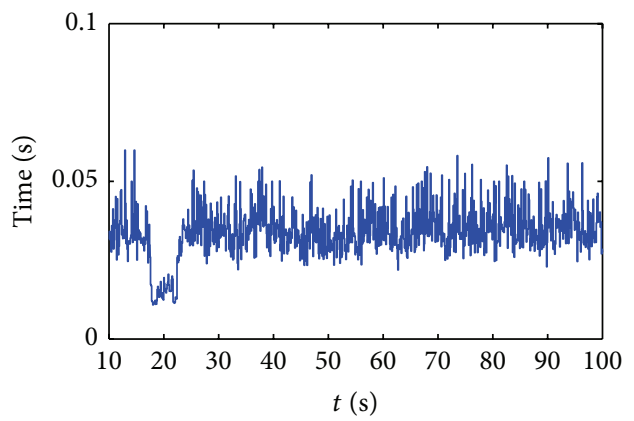

(l) Calculation time of the optimization model

FIGURE 6: Simulation results of the proposed control strategy.

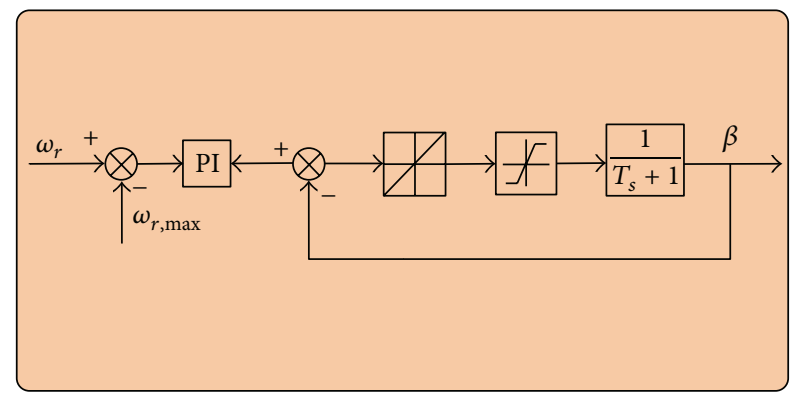

(a)

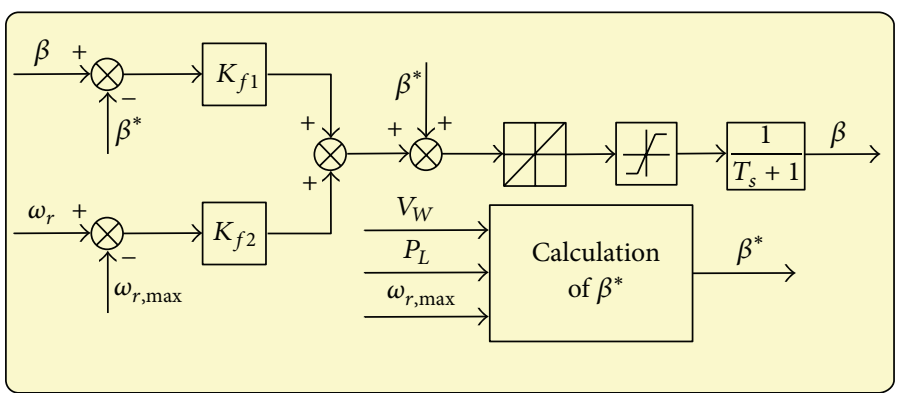

(b)

FIgURE 7: Schematic of the pitch system control strategy: (a) the strategy proposed in [10] and (b) the strategy proposed in [16].

TABLE 1: Comparison of the adjustment amount of rotating speed and pitch anglefor different control strategies.

\begin{tabular}{lccc}
\hline & $\Delta \omega_{r}$ & $\Delta \beta$ & $\Delta z$ \\
\hline This paper & 5.041 & 0.724 & 5.765 \\
Reference [10] & 5.325 & 1.105 & 6.43 \\
Reference [16] & 4.961 & 2.171 & 7.132 \\
\hline
\end{tabular}

\section{Conclusion}

This paper presents a novel control strategy to enable the DFIG to operate in the islanded mode. The control strategy is based on the optimal control of rotating speed and pitch angle of DFIG. Simulation results of the operation of a DFIG supplying a varying power load are given. Assuming that the capacity of DFIG is enough to satisfy the requirement of the active and reactive power of load simultaneously, the proposed control strategy presents several advantages as follows.

(1) The control strategy enables DFIG to control the frequency and amplitude of the stator voltage independently which is similar to a voltage source, and then it is not needed to equip a large power source to sustain the voltage of islanded power system.

(2) The improved control strategy of pitch system can make the rotating speed and pitch angle of DFIG track their reference values more quickly and accurately compared with other methods. 

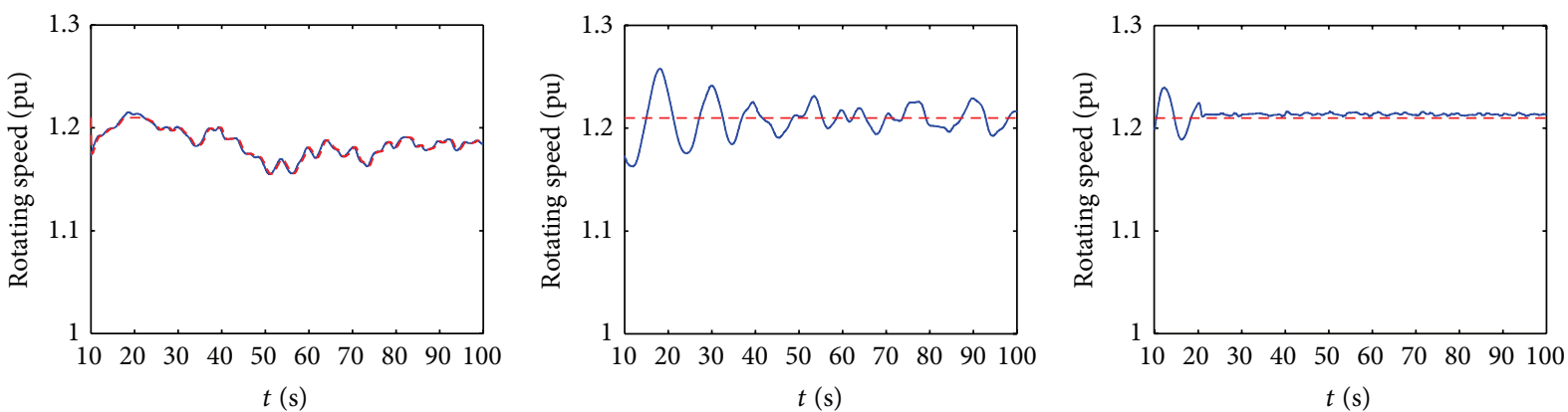

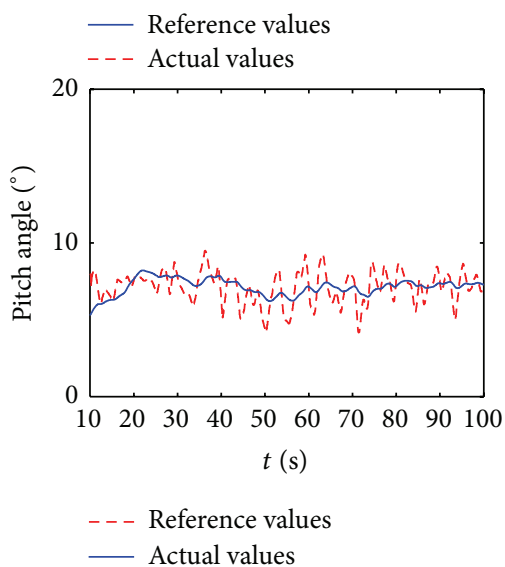

(a)

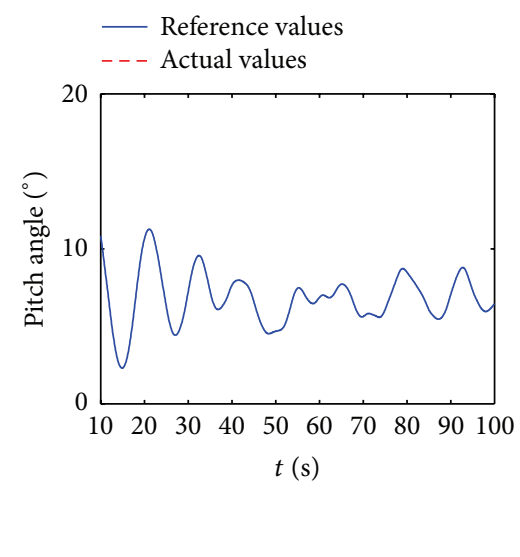

(b)

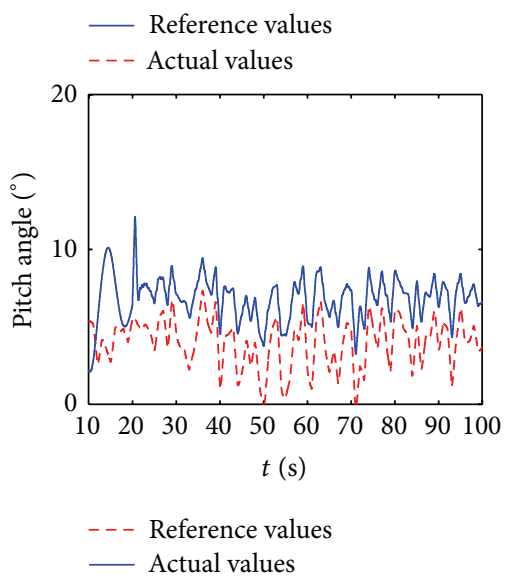

(c)

FIGURE 8: Rotating speed and pitch angle using the different pitch system control strategy: (a) the strategy proposed in this paper, (b) the strategy proposed in [10], and (c) the strategy proposed in [16].

(3) The application of this control strategy can ensure the DFIG to operate along the optimal transfer trajectory in islanded mode, with minimized adjustment amount of rotating speed and pitch angle.

Even if the DFIG may not track the maximum wind power, it is not necessarily a disadvantage for the islanded power systems in remote regions. The utilization efficiency of DFIG can be improved by equipping an energy storage system with appropriate capacity in the islanded power system. When the demand power of load is less than the extractable wind power of DFIG, the extra power can be absorbed by the energy storage system. Otherwise, the energy storage system can supply the load together with DFIG through releasing power. The coordinate control strategy of the DFIG and energy storage system will be fully addressed in the future publication.

\section{Conflict of Interests}

The authors declare that there is no conflict of interests regarding the publication of this paper.

\section{Acknowledgment}

This work was supported by the Science and Technology Project of State Grid Corporation of China under Grant SGMD0000DDJS1500096.

\section{References}

[1] G. Weidong, "Development and application of large-scale nongrid-connected wind power system," Automation of Electric Power Systems, vol. 32, no. 19, pp. 1-9, 2008.

[2] H. Yang, R. Zhao, H. Xin, Z. Wang, and D. Gan, "Development and research status of island power systems," Transactions of China Electrotechnical Society, vol. 28, no. 11, pp. 95-105, 2013.

[3] E. Guizzo, "Wind power in paradise," IEEE Spectrum, vol. 45, no. 3, pp. 38-45, 2008.

[4] G. Iwanski and W. Koczara, "DFIG-based power generation system with UPS function for variable-speed applications," IEEE Transactions on Industrial Electronics, vol. 55, no. 8, pp. 3047-3054, 2008.

[5] C. L. Moreira, F. O. Resende, and J. A. P. Lopes, "Using low voltage MicroGrids for service restoration," IEEE Transactions on Power Systems, vol. 22, no. 1, pp. 395-403, 2007.

[6] S. Müller, M. Deicke, and R. W. De Doncker, "Doubly fed induction generator systems for wind turbines," IEEE Industry Applications Magazine, vol. 8, no. 3, pp. 26-33, 2002.

[7] F. A. Bhuiyan and A. Yazdani, "Multimode control of a DFIGbased wind-power unit for remote applications," IEEE Transactions on Power Delivery, vol. 24, no. 4, pp. 2079-2089, 2009.

[8] S. Lin, L. Yi, and S. Nian, "A control strategy of isolated grid with high penetration of wind and energy storage systems," Proceedings of the CSEE, vol. 33, no. 16, pp. 78-85, 2013. 
[9] J.-Y. Kim, J.-H. Jeon, S.-K. Kim et al., “Cooperative control strategy of energy storage system and microsources for stabilizing the microgrid during islanded operation," IEEE Transactions on Power Electronics, vol. 25, no. 12, pp. 3037-3048, 2010.

[10] L.-R. Chang-Chien and Y.-C. Yin, "Strategies for operating wind power in a similar manner of conventional power plant," IEEE Transactions on Energy Conversion, vol. 24, no. 4, pp. 926-934, 2009.

[11] F. D. Kanellos and N. D. Hatziargyriou, "Optimal control of variable speed wind turbines in islanded mode of operation," IEEE Transactions on Energy Conversion, vol. 25, no. 4, pp. 11421151, 2010.

[12] Y. Zhang and B. T. Ooi, "Stand-Alone doubly-fed induction generators (DFIGs) with autonomous frequency control," IEEE Transactions on Power Delivery, vol. 28, no. 2, pp. 752-760, 2013.

[13] R. Cárdenas, R. Peña, J. Proboste, G. Asher, and J. Clare, "MRAS observer for sensorless control of standalone doubly fed induction generators," IEEE Transactions on Energy Conversion, vol. 20, no. 4, pp. 710-718, 2005.

[14] R. Pena, J. C. Clare, and G. M. Asher, "A doubly fed induction generator using back-to-back PWM converters supplying an isolated load from a variable speed wind turbine," IEE Proceedings-Electric Power Applications, vol. 143, no. 5, pp. 380387, 1996.

[15] R. D. Shukla and R. K. Tripathi, "A novel voltage and frequency controller for standalone DFIG based wind energy conversion system," Renewable and Sustainable Energy Reviews, vol. 37, pp. 69-89, 2014.

[16] M. Fazeli, G. M. Asher, C. Klumpner, and L. Yao, "Novel integration of DFIG-based wind generators within microgrids," IEEE Transactions on Energy Conversion, vol. 26, no. 3, pp. 840850, 2011.

[17] B. Boukhezzar and H. Siguerdidjane, "Nonlinear control of a variable-speed wind turbine using a two-mass model," IEEE Transactions on Energy Conversion, vol. 26, no. 1, pp. 149-162, 2011.

[18] A. Wächter and L. T. Biegler, "On the implementation of an interior-point filter line-search algorithm for large-scale nonlinear programming," Mathematical Programming, vol. 106, no. 1, pp. 25-57, 2006.

[19] A. Forsgren, P. E. Gill, and M. H. Wright, "Interior methods for nonlinear optimization," SIAM Review, vol. 44, no. 4, pp. 525597, 2002.

[20] R. A. Jabr, A. H. Coonick, and B. J. Cory, "A primal-dual interior point method for optimal power flow dispatching," IEEE Transactions on Power Systems, vol. 17, no. 3, pp. 654-662, 2002.

[21] W. Zheng and M. Liu, "Solution of optimal coordinated voltage control using line search filter interior point method," Transactions of China Electrotechnical Society, vol. 27, no. 9, pp. 70-77, 2012.

[22] T. Xianghong, B. Guangquan, and W. Hongfu, "An optimization method based on weighted least absolute value to restore power flow solvability of bulk power system," Automation of Electric Power Systems, vol. 38, no. 23, pp. 60-64, 2014.

[23] A. Wächter and L. T. Biegler, "Line search filter methods for nonlinear programming: motivation and global convergence," SIAM Journal on Optimization, vol. 16, no. 1, pp. 1-31, 2005. 


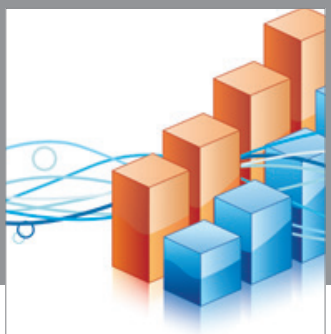

Advances in

Operations Research

vatem alat4

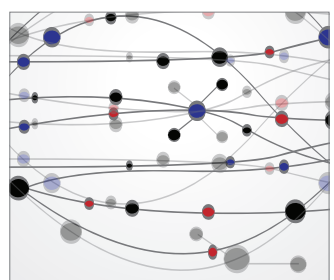

\section{The Scientific} World Journal
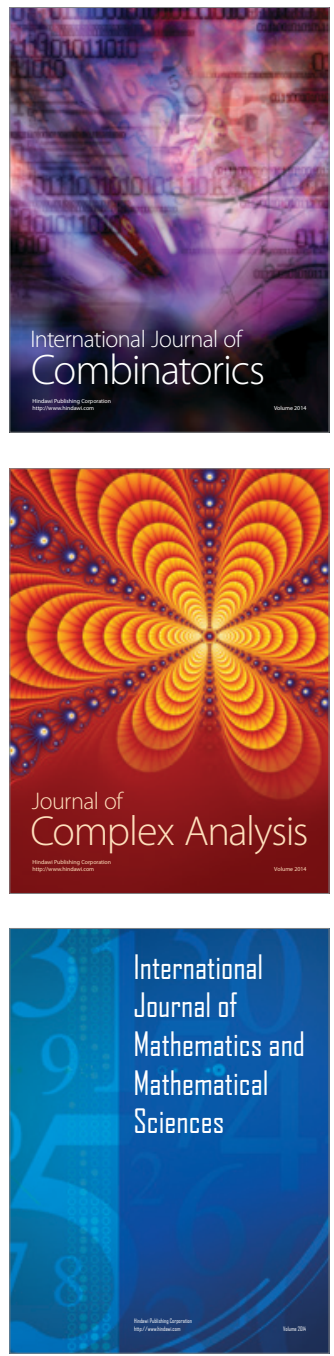
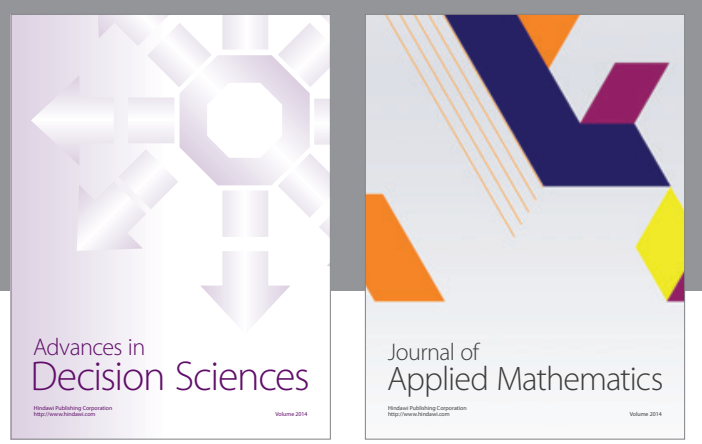

Algebra

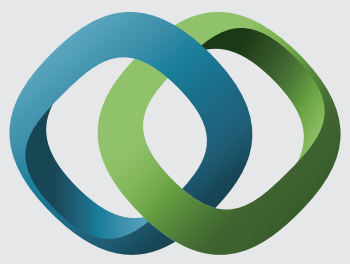

\section{Hindawi}

Submit your manuscripts at

http://www.hindawi.com
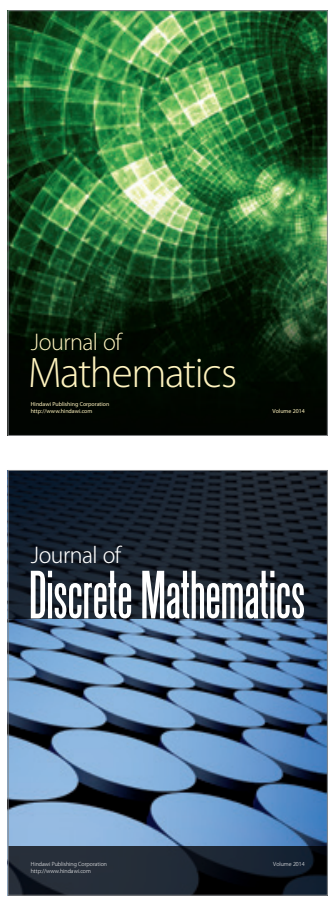

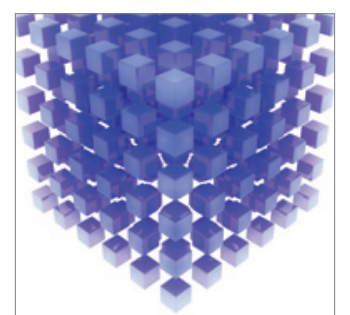

Mathematical Problems in Engineering
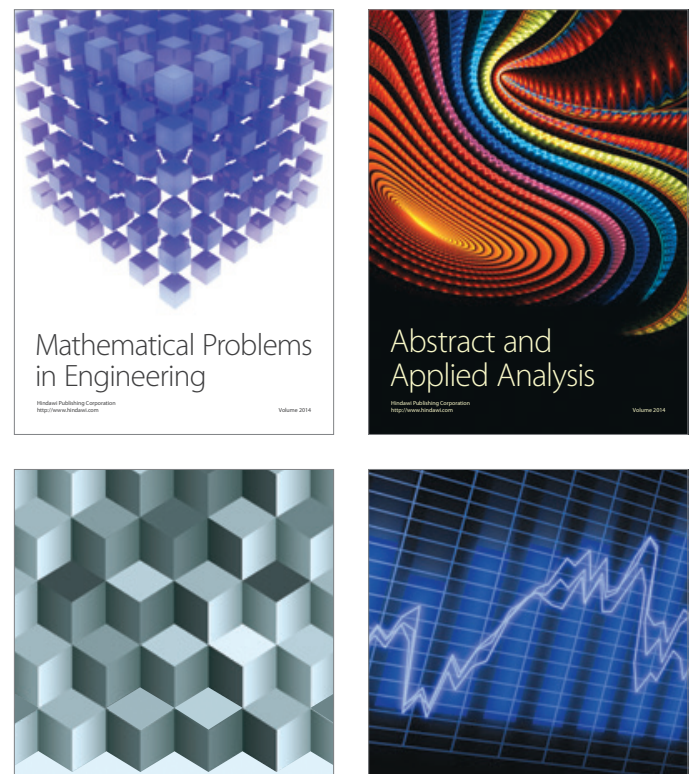

Journal of

Function Spaces

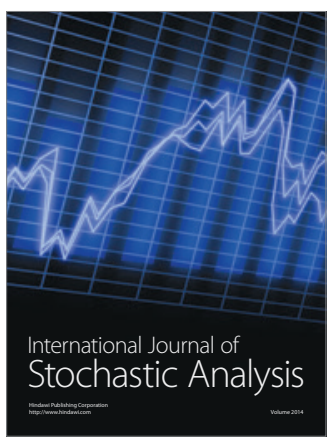

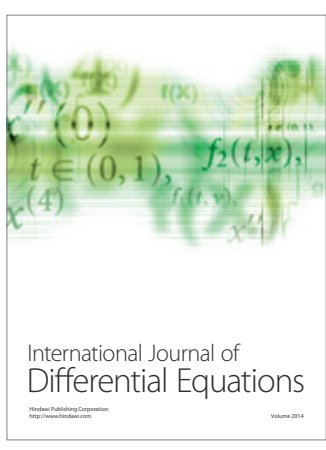
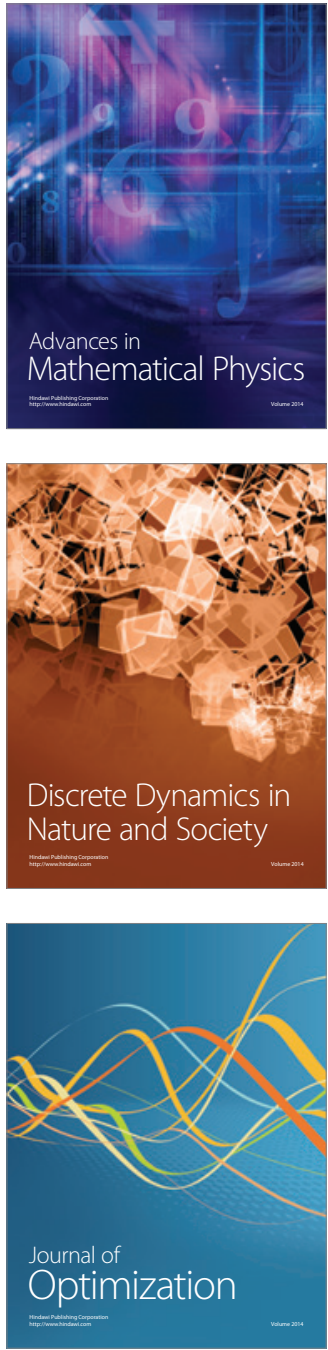